\title{
Reducing smoking in youth by a smoke-free school environment: A stratified cluster randomized controlled trial of Focus, a multicomponent program for alternative high schools
}

\author{
Gitte S. Jakobsen ${ }^{1}$, Dina Danielsen ${ }^{1}$, Marie P. Jensen ${ }^{1}$, Johan L. Vinther ${ }^{2}$, Charlotta Pisinger ${ }^{2,3}$, Teresa Holmberg', Rikke \\ F. Krølner', Susan Andersen ${ }^{1}$
}

\begin{abstract}
Youth smoking remains a major challenge for public health. Socioeconomic position influences the initiation and maintenance of smoking, and alternative high school students are at particularly high risk. The school environment is an important setting to promote health, however there is a lack of evidencebased school intervention programs. This article presents the Focus study, which aims to test the implementation and effectiveness of a school-based intervention integrating ${ }^{1}$ a comprehensive school smoking policy [i.e. smokefree school hours (SFSH) $]^{2}$, a course for school staff in short motivational conversations $^{3}$, school class-based teaching material ${ }^{4}$, an edutainment session5, a class-based competition, and6 access to smoking cessation support. Together these intervention components address students' acceptability of smoking, social influences, attitudes, motivation, and opportunities for smoking. The setting is alternative high schools across Denmark, and the evaluation design is based on a stratified cluster randomized controlled trial comparing the intervention group to a control group. Outcome data is collected at baseline, midway, and at the end of the intervention period. Moreover, a detailed process evaluation, using qualitative and quantitative methods, is conducted among students, teachers, and school principals. The results from this trial will provide important knowledge on the effectiveness of a smoke-free school environment. The findings will lead to a better understanding of which policies, environments, and cognitions, contribute to preventing and reducing cigarette use among young people in a diverse and high-risk school setting, and illuminate which complementary factors are significant to achieve success when implementing SFSH.
\end{abstract}

\section{AFFILIATION}

1 National Institute of Public Health, University of Southern Denmark, Copenhagen, Denmark 2 Department of Public Health, University of Copenhagen, Copenhagen, Denmark 3 Center for Clinical Research and Prevention, BispebjergFrederiksberg University Hospital, Copenhagen, Denmark

CORRESPONDENCE TO

Susan Andersen. National Institute of Public Health, University of Southern Denmark, Studiestræde 6, 1455, Copenhagen, Denmark. E-mail: suan@sdu.dk

ORCID ID: https://orcid.org/00000002-2741-0742

\section{KEYWORDS}

adolescents, social environment, tobacco prevention, alternative high school, school tobacco policies, intervention studies

Received: 16 December 2020 Revised: 2 March 2021

Accepted: 3 March 2021

\section{INTRODUCTION}

Tobacco use is the leading cause of preventable disease and premature death, and particularly in Europe and North America, and smoking imposes a heavy health burden and labor loss ${ }^{1}$. The prevalence of smoking has been declining in Europe, which is mainly related to more restrictive national regulations and tobacco tax increases that have been introduced over time ${ }^{2}$. In Denmark, the smoking prevalence has declined in all age groups except for adolescents and young adults ${ }^{3}$. The majority of smokers start smoking at an early age and it is estimated that smoking uptake peaks at 16 years ${ }^{4}$. Furthermore, adolescents are particularly susceptible to nicotine addiction ${ }^{5}$. Thus, youth smoking remains a major challenge for public health. A lower socioeconomic position (SEP) 
increases the risk of initiation and maintenance of smoking as well as heavy smoking ${ }^{6}$. In Denmark, students with a lower SEP are more often attracted to alternative high schools (AHS). The structure of teaching at AHSs is accommodated to fit students with special academic and emotional needs, e.g. by higher teacher to student ratios and shorter school days ${ }^{7}$. As other types of schools, the AHS is an important setting in order to prevent youth smoking ${ }^{8}$.

School-based interventions often use health educational strategies to improve knowledge related to substance use. However, such interventions often show disappointing results ${ }^{9,10}$. Moreover, systematic reviews have shown limited evidence of smoking cessation interventions on smoking cessation or reduction in young people aged $\leq 20$ years $^{11}$ and aged 18-24 years ${ }^{12}$. Nevertheless, findings support group counseling ${ }^{11}$, quit-and-win contests ${ }^{12}$ and smoking cessation services (e.g. quitlines) ${ }^{13,14}$. In recent years, there has been an increased awareness of how modifications of the school's social and/or physical environment can promote students' health, which indicates that the context is significant ${ }^{15}$. However, the evidence for this approach is relatively weak, in part because of difficulties related to both implementation and evaluation ${ }^{16}$.

One way to intervene in the school smoking context is by implementing school tobacco policies (STPs) aiming at reducing smoking. Smoking policies in schools have not been studied to the same extent as smoking cessation interventions ${ }^{17}$. In addition, the studies available are concentrated to a large extent on the primary or lower secondary school level. A review of 31 studies concluded that the evidence of STPs is insufficient ${ }^{10}$. However, the authors highlighted some promising elements, including comprehensive and clear bans that apply to all, consistent enforcement by both pupils and adults at school, and the presence of education and prevention programs. Recent studies on STPs at 50 schools in six European cities (data from the SILNE-R surveys among students aged 14-17 years) found that STPs reduce smoking on school premises and reduce occasional smoking ${ }^{18}$ but no effect was found on daily smoking ${ }^{19}$. Danish studies have shown that in AHSs, smoking plays a central role in social interactions among students, and the school context may increase the students' use of cigarettes by creating peer groups around the use of cigarettes ${ }^{20}$. Moreover, students with lower levels of academic achievement are more likely to engage in cigarette smoking ${ }^{7,21}$. A few interventions have been implemented at AHSs with some success, for example school tobacco policies and smoking cessation programs ${ }^{7}$, but most smoking interventions targeting youth have concentrated on smoking initiation. In addition, young people seldom perceive themselves as 'smokers' and therefore, smoking cessation programs may not appeal to them. The path and change from experimenting with smoking to becoming a regular smoker is often long. Thus, an important focus is to prevent experimental smoking escalating ${ }^{22}$. Effective and feasible interventions are crucial to help young people quit smoking and preventing regular smoking. Moreover, further research is required to assess the effectiveness of interventions as well as which type of intervention components is significant on reduction and prevention of smoking in youth.

\section{Aims}

This article presents the protocol for a stratified cluster randomized controlled trial Focus implemented in diverse Danish AHSs. The aim of the Focus study is to develop, implement, and evaluate a multi-component intervention to minimize the number of new smokers and reduce daily smoking among students attending AHSs through promotion of a smoke-free school environment (i.e. SFSH). The primary hypothesis for this study is that the intervention will lead to a $25 \%$ reduction in number of cigarettes smoked per day during the 4-month period.

\section{METHODS}

\section{Study design}

The Focus study is a two-armed cluster randomized controlled trial (C-RCT) comparing the Focus intervention with normal practice. We combine the C-RCT with a qualitative and quantitative process evaluation. Process evaluation is recommended by Medical Research Council guidance ${ }^{23}$, particularly for complex interventions that include several interacting components. If outcome evaluation is done in isolation, it may leave essential questions unanswered such as what can be improved if the intervention is proved ineffective or has different 
effects in different contexts. The study can therefore also be characterized as a hybrid design ${ }^{24}$ which combines the C-RCT with quantitative and qualitative implementation and process evaluation studies based on ethnographic field work, interviews and questionnaires to principals, teachers and students at the participating schools. The intervention will run over two periods, from August 2018 to January 2019 and from August 2019 to January 2020, and includes different schools across Denmark in each period. Each intervention period will include four schools in the intervention group and three in the control group. Data will be collected during the two intervention periods at baseline, midway (first follow-up), and at the end of the intervention period (second follow-up).

The study is registered as ISRCTN16455577 in the ISRCTN trial registry.

\section{Setting}

The study targets young individuals aged 16-25 years attending vocational schools or preparatory Basic Education (PBE) (both named 'alternative high schools' or 'AHS' in this article) and is conducted across Denmark. The Danish school system includes compulsory primary school of 10 years (0-9th grade) with an optional upper secondary education. The upper secondary education is divided into general high school, technical and commercial high school, and vocational education and training (VET) (e.g. health care, business service, agriculture, construction, and transportation). This study engages schools offering a range of vocational education, including commercial, technical, and social and health education. A few of the schools also offer higher technical or commercial programs, which aim at higher education comparable to the general high school. Also, schools offering PBE are included in the study. The duration of PBE is up to two years and is offered to individuals below 25 years who need professional or personal upgrading to complete their youth education (i.e. high school) or vocational qualifications to get into the labor market ${ }^{25}$.

\section{Inclusion criteria}

Eligible schools included Danish alternative high schools that: 1) offer basic VET or PBE, 2) have at least 100 students enrolled in the basic program (first school year) at vocational schools or in total at PBE schools, 3) not have introduced school tobacco policy with smoke- free school hours, 4) are willing to implement the Focus intervention program and adhere to evaluation procedures (i.e. participate in the data collection and field work conducted by the researchers), and 5) accept the randomization of the intervention. In total, 62 VET schools and 8 PBE schools are invited by e-mail or phone and 14 schools are included in the study (Figure 1). Some of the included schools are larger organizations with several independent school units at different addresses (e.g. in separate cities).

\section{Recruitment and randomization procedure}

Initially, the research team contacted 62 VET schools following the propensity sampling method. Due to challenges with inclusion of VET schools offering technical programs and time constraints, the research team decided to expand the intervention to also comprise PBE schools as the students at VET schools and PBE schools seem comparable in SEP and smoking habits. In order to detect PBE schools relevant for inclusion, the research team contacted a principal at a PBE school with SFSH who keeps in touch with other PBE schools via networks. The principal assisted in indicating relevant schools that might be interested in participating in the Focus study following the convenience sampling method. The research team contacted school principals via telephone and invited their school to take part in the study. If the school was willing to participate, the school principal signed and returned a written consent form to the research team. The schools were randomized into intervention or control groups by a statistician not part of the research team. Stratified randomization was accomplished by computer-based random number generation and the statistician was blinded in the randomization process. Stratification factors are school type (PBE, social and health education, commercial, and technical education) and geographical location to reduce selection bias and achieve sample size balance across the arms. However, one school offering PBE withdraw from participation after being allocated to the control group due to the fact that the school already had decided to implement SFSH at the time of the intervention's start and thus, did not wish to be part of the control group. Subsequently, another school offering PBE was invited to be included in the control group without randomization and this school accepted the invitation. 
Figure 1. Flow diagram of ranodmization, and participation in the Focus study

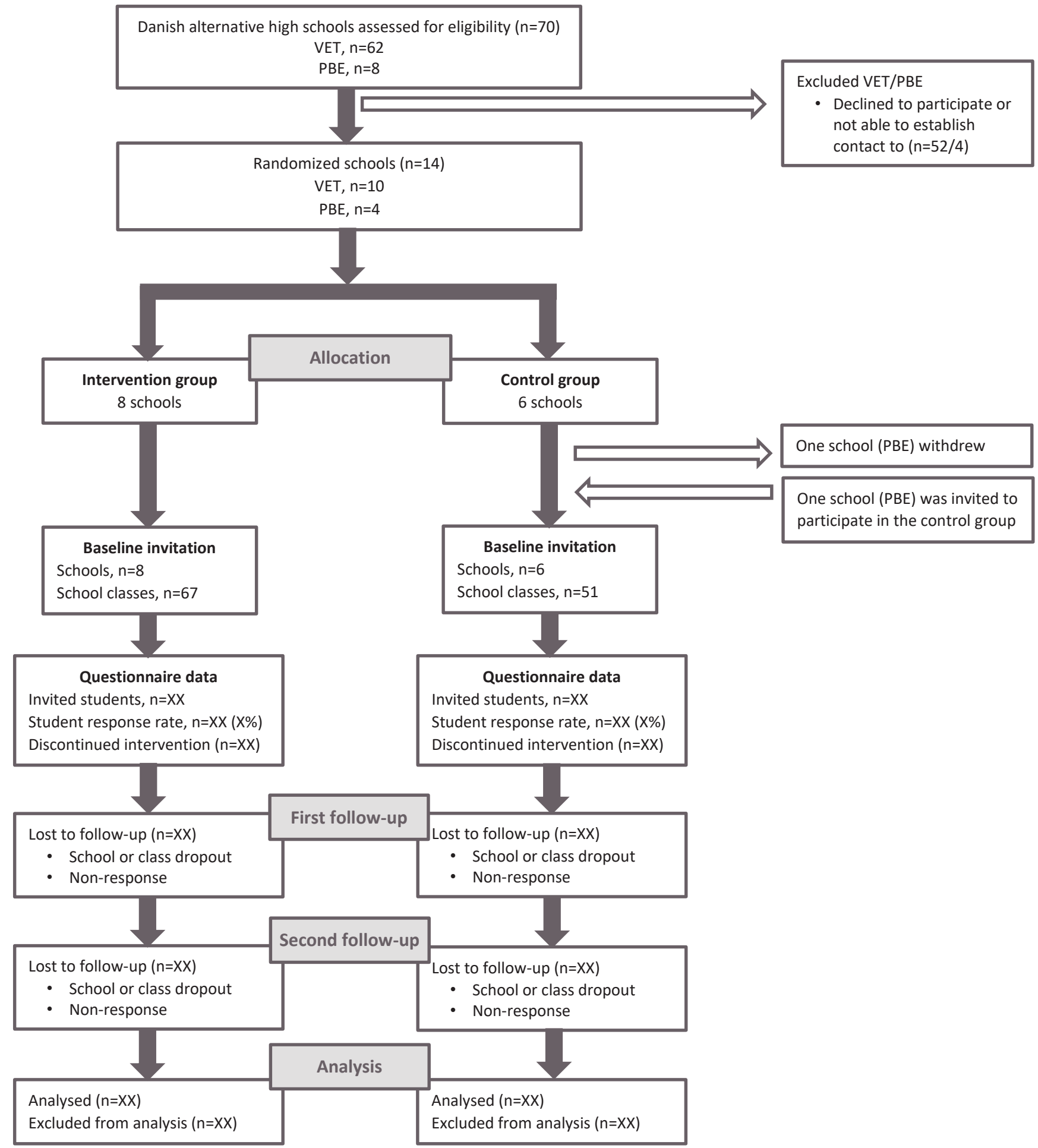

The school principals are informed of the results of the randomization by e-mail. Each intervention school is visited by the research team to discuss the implementation process and informed about data collection. The control schools are informed about the data collection by e-mail. 


\section{The focus intervention}

Briefly, the Focus intervention is developed based on the Intervention Mapping (IM) framework ${ }^{26}$ and Behavior Change Wheel (BCW) model ${ }^{27}$, and guided by self-determination theory ${ }^{28}$ and social-ecological theories. Prior to the intervention, a comprehensive needs assessment was carried out (January-August 2017) following two pilot studies, where part of the intervention was tested (September-December 2017). The intervention program involves six components:

1. School smoking policy - enforcement of SFSH composed by the school management (i.e. staff and students are not allowed to smoke during school hours). The aim is to change the school practices by limiting smoking visibility, accessibility, and acceptability.

2. Two-day course for school staff in short motivational counselling about smoking - 2 to 4 teachers, student counselors, and other relevant staff at the intervention schools will be invited to take part in a course on motivational counseling with young individuals arranged by the Danish Cancer Society. The aim of the course is to train school staff to counsel students on how to manage SFSH.

3. School class-based teaching material - eight sessions directed at attitudes, beliefs, and social influence aiming at starting a reflection phase assessing and supporting the students' individual awareness and interest in reducing, quitting, or not initiating smoking. The themes of the teaching material aim to: correct adolescents' misperceptions, i.e. overestimation of smoking prevalence; increasing students' awareness of peer and family influences and high-risk situations; challenge students' beliefs about the social and psychological benefits of smoking; provide opportunities for students to discuss how to build positive peer relations; and implement social activities during breaks to offer social alternatives to smoking.

4. Edutainment session - an entertaining talk on smoking (named 'Act on it') performed by an actor. The purpose of the session is to inform students about nicotine dependency and consequences of smoking, and advice on how to manage a school day without smoking and encourage students not to smoke during the school day. Another objective is to inform students that their individual risk of illness is personally relevant and correct the current misperception among young individuals that they are capable of quitting smoking at any time.

5. Class-based competition based on measurements of carbon monoxide levels - students will be invited to participate in a competition by agreeing to get their carbon monoxide levels in their breath measured twice: at baseline and after two months. The school class with the largest overall reduction or maintenance of a low carbon monoxide level will win a prize. The aim of the competition is to motivate students to support each other in preventing or reducing smoking and enlighten students about how their smoking behavior affects carbon monoxide levels.

6. Access to smoking cessation support offered by the National Quitline - students or staff who wish to seek help quitting or handling smoking during the school day will have the option to give their phone number during the edutainment session or send a text message to the National Quitline (www. stoplinien.dk). Within two weeks, the National Quitline will then call them and offer three free sessions of telephone counseling for smoking cessation or smoking reduction. The aim of these sessions is to provide quit strategies and guidance with support and feedback from a familiar counselor. The support shall help students find motivation, confidence, and skills for lasting change or to provide guidance on managing SFSH.

Figure 2 summarizes the program theory of the Focus intervention.

\section{Data collection}

Longitudinal data will be collected from selfadministered internet-based questionnaires. A sample of students at intervention and control schools will be invited to answer questionnaires about smoking, health behavior, and wellbeing. The sample comprises all students allocated to participate in all of the Focus intervention components; typically, all students enrolled in the first part of the basic program (first 6 months of school) and typically all students at PBE schools. Moreover, we asked the schools to include at least two other school classes, if possible [typically students enrolled in the second part of the basic program (next 6 months of school)] at VET schools. The students will answer a questionnaire within the first week of school (baseline), midway 
Figure 2. Program theory for the Focus intervention

\begin{tabular}{|c|c|c|c|c|}
\hline $\begin{array}{l}\text { INTERVENTION } \\
\text { COMPONENTS }\end{array}$ & $\begin{array}{l}\text { IMPLEMENTATION } \\
\text { PROCESSES }\end{array}$ & OUTPUT & PROXIMAL OUTCOMES & DISTAL OUTCOMES \\
\hline $\begin{array}{l}\text { Smoke-free school hours } \\
\text { Course for staff members in } \\
\text { short motivational } \\
\text { conversations about smoking } \\
\text { School class-based teaching } \\
\text { material about social relations } \\
\text { and smoking } \\
\text { Edutainment session } \\
\text { Class-based competition } \\
\text { Access to smoking cessation } \\
\text { support }\end{array}$ & $\begin{array}{l}\text { Policies for enforcement } \\
\text { practices } \\
\text { Curricular activities } \\
\text { Improved communication and } \\
\text { teacher competencies to } \\
\text { support smoking cessation } \\
\text { and how to handle a smoke- } \\
\text { free school day } \\
\text { Motivational support activities }\end{array}$ & $\begin{array}{l}\text { Environmental level: } \\
\text { Less visibility of smoking } \\
\text { Less accessability of cigarettes } \\
\text { Less acceptability of smoking } \\
\text { Improved access to smoking } \\
\text { cessation support } \\
\text { Interpersonal level: } \\
\text { Improved social relationships } \\
\text { at school (not related to } \\
\text { smoking) } \\
\text { Reduce socializing around } \\
\text { smoking } \\
\text { Individual level: } \\
\text { Less positive beliefs about } \\
\text { social and psychological } \\
\text { benefits of smoking } \\
\text { Improved smoking-related } \\
\text { self-efficacy }\end{array}$ & $\begin{array}{l}\text { Environmental level: } \\
\text { Denormalized (descriptive) } \\
\text { social norms for smoking at } \\
\text { school level } \\
\text { Interpersonal level: } \\
\text { School connectedness } \\
\text { Individual level: } \\
\text { Decreased intention to initiate } \\
\text { smoking } \\
\text { Increased intention to quit } \\
\text { smoking }\end{array}$ & $\begin{array}{l}\text { Prevention of smoking uptake } \\
\text { among non-smokers } \\
\text { Prevention of daily smoking } \\
\text { among occasional smokers } \\
\text { Increase of smoking cessation } \\
\text { or reduction of cigarettes per } \\
\text { day among daily smokers } \\
\text { Decrease of nicotine } \\
\text { dependence }\end{array}$ \\
\hline
\end{tabular}

at first follow-up (2-3 months after baseline), and at second follow-up (4-5 months after baseline). At baseline and second follow-up, the students answer the questionnaire during school time. The duration of the baseline questionnaire is approximately 10 minutes whereas the second follow-up questionnaire is an extended version of the baseline questionnaire with a duration of approximately 15 minutes. At baseline, the students have the possibility of listening to questions through headphones while answering. Baseline assessment is not possible before school start, because school student records are incomplete. Moreover, baseline data are collected at school to reduce non-response ${ }^{29}$. At baseline and second followup, students are asked to provide their e-mail and cell phone number. The students who provide their cell phone number in the baseline questionnaire will receive a short follow-up questionnaire via text message, midway in the intervention period (duration: approximately 3 minutes). To maximize the response rate, students will have a chance to win tickets to the cinema when answering the first followup questionnaire. Follow-up of graduated students and non-respondents in follow-up assessment will be conducted by text message and e-mail, if possible. Table 1 presents an overview of the collected student data. As elaborated below, the student questionnaire items are based on Danish population surveys and validated scales, when possible. The questionnaires were subject to an expert hearing followed by pilot testing among students $(n=47)$ in four vocational schools (not included in the intervention study). The pilot test focused especially on items developed specifically for the Focus study by the research team. The questionnaires were kept as short as possible in order to increase the response rate.

Principals and teachers at the intervention schools will answer a questionnaire about school characteristics and implementation readiness $\mathrm{s}^{30}$ before school start (baseline) and a questionnaire about implementation of the intervention components at the end of the intervention. To assess activities at control schools, principals at the control schools will be interviewed by telephone or receive a questionnaire about smoking policies and social initiatives at 3 months. 
Table 1. Timing of data collection

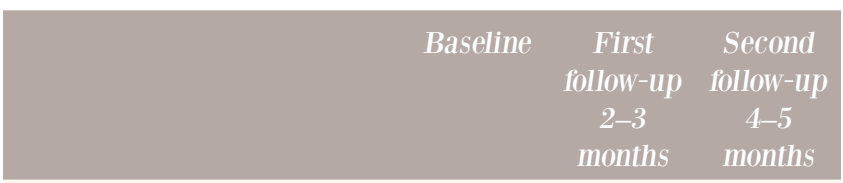

Personal characteristics

Sex, age, ethnic origin, parental ethnic origin, parental job position and workplace, living arrangement

Smoking durationa and debut

Smoking among relatives and friends

Self-reported causes of smoking

Primary outcome

Cigarettes per day

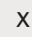

Secondary outcomes

Smoking status (cigarettes)

Nicotine dependence

Cigarettes per day at schoola

Perceived estimate of peer

smoking prevalence

Perceptions of students

smoking

Perceptions of school staff smoking $^{\text {a }}$

School connectedness

Intention to initiate smoking

Readiness to quit smoking

Perceived access to and use of smoking cessation support ${ }^{\mathrm{a}}$

A sense of community in class

Perceived student and teacher support

Beliefs about social and psychological benefits of smoking $^{\text {a }}$

Smoking-related self-efficacy

Unintended outcomes

Use of snuff, hookah,

e-cigarettes ${ }^{a}$

Use of cannabis ${ }^{\mathrm{a}}$

Stigmatization related to

smoking

Boredom during classes and

breaks $^{\mathrm{a}}$

Loneliness

Stress ${ }^{15}$

a Self-invented items.

\section{Outcome measures}

All measures are self-reported. Primary, secondary, and unintended outcome measures are reported by students. The majority of the items in the student questionnaire are derived from the Danish National Youth Study ${ }^{31}$; a national survey among general and alternative high school students conducted in 2014 supplemented with items from other studies, including the Danish National Health Survey ${ }^{32}$ and the Danish X:IT study on smoking among school-aged children ${ }^{33}$. Items are transferred directly or adjusted according to the target group. We developed new items if validated questions did not already exist. See Figure 2 for program theory and Table 1 for timing of data collection.

\section{Primary outcome measure}

The primary outcome measure of the study is cigarette intensity measured by number of cigarettes per day following the Heaviness of Smoking scale (HSI) ${ }^{34}$; 'How many cigarettes do you typically smoke per day?' (State the average number of cigarettes).

\section{Secondary outcome measures}

Measures related to the distal outcomes include smoking status (present and former), nicotine dependence measured by the Heavy Smoking Index (HSI) by combining 'time to the first cigarette of the day' and daily cigarette quantity ${ }^{34}$, and number of cigarettes per day at school. Measures expected to influence these outcomes include descriptive social norms for smoking at school level measured by perceived estimate of peer smoking prevalence ${ }^{35}$ (e.g. 'How many students at school do you think smoke daily?'), school connectedness, intention to initiate smoking (among non-smokers), and intention to quit smoking (among smokers). Measures related to the immediate outcomes include visibility of smoking measured by perceptions of student smoking at school and class level and school staff smoking (selfinvented) (e.g. 'How often do you see teachers or other staff smoke during school hours?'), perceived access to and use of smoking cessation support, a sense of community in class, perceived student and teacher support, beliefs about social and psychological benefits of smoking, and smoking-related self-efficacy (among smokers, e.g. 'Do you think you are able not to smoke if your friends offer you a cigarette, if you feel nervous', etc.). 


\section{Unintended outcomes}

Use of e-cigarettes, hookah, snuff, and cannabis, as an alternative or supplement to cigarettes is measured. Also, stigmatization related to smoking is measured according to the Internalized Stigma of Smoking Inventory using relevant items from subscales on selfstigma, felt stigma, and discrimination. Items were translated from English to Danish ${ }^{36}$. Negative mental health is measured by boredom (during classes and breaks), loneliness, and stress.

\section{Covariates}

Personal characteristics such as sex, age, and ethnic origin are measured, (Table 1). Further, smoking duration and smoking debut, and smoking prevalence among relatives and friends are measured. Also, respondents were asked to state their Central Personal Registration number at follow-up. This information will make it possible to draw information on parental jobs, income etc., from Danish registers.

\section{Measures of implementation readiness and implementation of the intervention components} Implementation readiness is measured in the principal and teacher questionnaires based on the model for organizational readiness described by Scaccia et al. ${ }^{30}$. Implementation of the intervention components will be measured in the student questionnaires at second follow-up and in the principal and teacher questionnaires at first follow-up. The conceptualization of implementation is based on the implementation fidelity framework described by Carroll et al. ${ }^{37}$ and includes measures of adherence (content, coverage, frequency, duration), dose, participant responsiveness, and quality of delivery of each intervention component where relevant. The majority of these items were selfinvented, while some were inspired by Danish studies on smoking among lower secondary school students. Based on the implementation fidelity measures, we will develop quantifiable measures for implementation at the organizational and individual level based on an approach described by Ferm et al. ${ }^{38}$. In this method, weighted implementation scores from 0-100 are calculated for each intervention component based on a priori explicitly formulated success criteria.

\section{Sample size}

Sample size calculations show that 10 schools with an average of 100 students (i.e. five schools in the intervention group and five schools in the control group; in total 1000 students) is necessary to detect a $25 \%$ reduction in the number of cigarettes smoked per day (e.g. from 15 cigarettes to 11 cigarettes among daily smokers) at the follow-up (post-intervention) at 4 months, with a power of $80 \%$ and an alpha of $5 \%$. The cluster design is taken into account with an assumed intra-cluster correlation coefficient for schools (ICG) of 0.025. The ICC is estimated based on data from the Danish National Youth Study 2014. Allowing for $20 \%$ loss to follow-up, approximately 1250 students need to be included in the study.

\section{Statistical analysis}

Intervention effects will be evaluated by multilevel regression models accounting for the hierarchical data structure, e.g. students nested within classes nested within schools. We will analyze differences in primary and secondary outcome measures between intervention and control groups. The analyses will be adjusted for baseline smoking status and sociodemographic factors such as sex, age, SEP, smoking in the social network, and the balancing factor (school type) used for the stratified randomization. Handling of missing data will be conducted based on analysis of loss to follow-up. Missing data might be handled with multiple imputation. Independent general linear models will be fitted for the continuous outcome variables and logistic regression models for the categorical outcomes. Sociodemographic differential effectiveness of the interventions will be examined by subgroup analysis defined by sex, age, and SEP (in students). Furthermore, we will examine the association between implementation degree and the effect of the intervention and investigate associations between contextual factors and implementation degree.

Finally, we will investigate the contextual influences on the implementation process and the association between implementation and effect.

\section{Qualitative methods}

Qualitative methods are appropriate to investigate participant perceptions and experiences of the intervention, as well as understand contextual influences on the implementation process ${ }^{39}$. We will use ethnographic fieldwork within school hours and 
breaks, semi-structured focus-groups with students and teachers, and individual semi-structured interviews with school principals for method triangulation. Ethnographic fieldwork offers insights into social and cultural norms that occur and are maintained within local contexts and social settings. Hence, ethnographic fieldwork provides entry to the field, experiences of everyday life in alternative high school settings, and the possibility of experiencing how SFSH are implemented and visible in everyday social processes at school.

We will use focus groups to investigate social norms, perceptions, and interactions among students and teachers in the context of alternative high schools. Also, focus groups are suitable to capture the social processes, such as discussions and reactions, and group dynamics within social groups ${ }^{40}$. Moreover, focus groups are used as a methodological tool to gain a deeper understanding of the field work findings and inquire about the possible hypothesis arising from these. We will conduct semi-structured individual interviews with school principals. These interviews are useful to explore school principals' subjective experiences and perspectives on SFSH and the implementation process ${ }^{41}$.

The analytical approach for the qualitative study is based on abduction ${ }^{42}$. Collection and analysis of empirical data will be preceded by theoretical studies, and combined with theory as a source of inspiration for discovering patterns leading to further understanding and interpretation $\mathrm{s}^{42}$. Inspirations from social interactionism ${ }^{43}$ and social constructionism ${ }^{44}$ will form the analytical framework allowing us to identify the social processes and interpersonal dynamics that constitute institutional life and room for action in schools and thus, the conditions for implementing the Focus intervention. Specifically, the qualitative data will be analyzed as a thematic analysis ${ }^{45}$ guided by the research questions and the previously mentioned theoretical inspiration, also paying attention to themes arising from the field observations and participants' perspectives and experiences.

\section{Ethics}

The study is carried out in accordance with current Danish rules of ethics and legislature and has been approved by the Danish Data Protection Agency
(Ref: 17/12006). The National Committee on Health Research Ethics concluded that formal ethics approval was not required because no human biological material was sampled (Ref: 20182000-83). There is no formal institution for ethical assessment and approval of register- and questionnaire-based population studies in Denmark. The study will be introduced to the students as a study about smoking, health behavior, and wellbeing. The students will be informed that participation is voluntary, that their information will be used for research purposes only and treated confidentially and they will be given the opportunity to withdraw from the study during the entire study period.

\section{DISCUSSION}

This article describes the protocol for a cluster randomized controlled trial to determine the effectiveness of a school-based intervention aimed at minimizing smoking among AHS students. The Focus study will contribute with new and important knowledge on multi-component interventions targeting smoking behavior among adolescents. The results from the study will provide knowledge on the effectiveness of a smoke-free school environment and findings will lead to a better understanding of policies, environments, and cognitions that contribute to preventing and reducing cigarette use among young individuals in a widely diverse and highly exposed school setting. Furthermore, the Focus study will give insights to challenges of working with young individuals with lower SEP in intervention research. This will lead to important knowledge for evidenceand practice-based recommendations to AHSs, politicians, and other stakeholders.

\section{Strengths and limitations}

Strengths of the Focus study are: 1) the use of the Behavior Change Wheel for systematically designing and planning the intervention and the evaluation design based on theory and evidence; 2) use of a multi-component intervention approach to target determinants at multiple levels; 3 ) use of a randomized controlled trial design; 4) inclusion of a wide range of quantitative measures of aspects related to smoking in an alternative high school setting; 5) a comprehensive theory-based process evaluation design; 6) a thorough investigation of implementation 
fidelity including the development of quantifiable measures for implementation; 7) use of measurements at both principal, teacher, and student level; and 8) use of advanced statistical analyses.

The Focus study has some limitations that must be considered. We use a healthy setting approach. The healthy setting approach has been criticized for being a relatively weak evidence base for efficacy ${ }^{12,24}$ because few studies focus on comprehensive programs and there are problems with both implementation and evaluation ${ }^{12,25}$. Moreover, the Focus study may be subject to history bias due to the evaluation design with relatively few cluster units, which may imply that the randomization process has not succeeded in comparable intervention and control groups. However, with the stratified randomization method we address this concern and in the statistical analyses, we will control and balance the influence of important covariates. Another concern is that the PBE institutions will undergo a transformation to a different structure possibly with changes in the school management during the Focus study which might give rise to implementation challenges. Implementation challenges are notorious in school-based interventions and thus, an issue of concern in this study. However, the implementation will be thoroughly analyzed via questionnaires to principals and teachers and through ethnographic fieldwork. Moreover, a realistic review ${ }^{17}$ has demonstrated how STPs can trigger cognitive and behavioral responses to reduce smoking. The challenges are to: 1) stop students to find alternative place to smoke; 2 ) avert students from developing counterproductive views about the purpose (e.g. rules exist only to protect the reputational standing of the school) and legitimacy (e.g. school violates their right to smoke); 3 ) prevent smoking outside the school premises, as it is more visible and the temptation greater; and 4) prevent inconsistent enforcement by staff who undermine adequate implementation ${ }^{17,46}$. This will be investigated through the process evaluation.

\section{CONCLUSIONS}

This is the first study with an RCT design that investigates the effect of SFSH in AHSs in Denmark. If effective, Focus is expected to have a sustainable impact on the reduction of youth smoking. There is a need for evaluation of interventions on students' smoking behavior, and especially in adolescents with low SEP. With a detailed process evaluation including qualitative and quantitative methods among students, teachers, and principals in the AHS setting, the Focus study will provide important knowledge on the effectiveness of a smoke-free school environment. The findings will lead to a better understanding of which policies, environments, and cognitions contribute to preventing and reducing cigarette use among young people in a diverse and high-risk school setting and illuminate which complementary factors that are significant to achieve success when implementing SFSH.

\section{REFERENCES}

1. Goodchild M, Nargis N, Tursan d'Espaignet E. Global economic cost of smoking-attributable diseases. Tob Control. 2018;27(1):58-64. doi:10.1136/tobaccocontrol-2016-053305

2. Hoffman SJ, Tan C. Overview of systematic reviews on the health-related effects of government tobacco control policies. BMC Public Health. 2015;15(1):744. doi:10.1186/s12889-015-2041-6

3. Jarlstrup NS, Juel K, Pisinger CH, Grønbæk M, Holm $\mathrm{S}$, Andersen S. International approaches to tobacco use cessation programs and policy in adolescents and young adults: Denmark. Curr Addict Rep. 2018;5(1):42-53. doi:10.1007/s40429-018-0187-x

4. Nuyts PAW, Kuipers MAG, Willemsen MC, Kunst AE. Trends in age of smoking initiation in the Netherlands: a shift towards older ages? Addiction. 2018;113(3):524532. doi:10.1111/add.14057

5. Prokhorov AV, Winickoff JP, Ahluwalia JS, et al; Tobacco Consortium, American Academy of Pediatrics Center for Child Health Research. Youth tobacco use: a global perspective for child health care clinicians. Pediatrics. 2006;118(3):e890-e903. doi:10.1542/peds.2005-0810

6. Clare P, Bradford D, Courtney RJ, Martire K, Mattick RP. The relationship between socioeconomic status and 'hardcore' smoking over time-greater accumulation of hardened smokers in low-SES than high-SES smokers. Tob Control. 2014;23(e2):e133-e138. doi:10.1136/tobaccocontrol-2013-051436

7. Sussman S, Arriaza B, Grigsby TJ. Alcohol, tobacco, and other drug misuse prevention and cessation programming for alternative high school youth: a review. J Sch Health. 2014;84(11):748-758. doi:10.1111/josh.12200

8. Henderson M, Ecob R, Wight D, Abraham C. What explains between-school differences in rates of smoking? BMC Public Health. 2008;8:218. doi:10.1186/1471-2458-8-218

9. Thomas RE, McLellan J, Perera R. School-based programmes for preventing smoking. Cochrane 
Database Syst Rev. 2013;2013(4):CD001293. doi:10.1002/14651858.CD001293.pub3

10. Coppo A, Galanti MR, Giordano L, Buscemi D, Bremberg S, Faggiano F. School policies for preventing smoking among young people. Cochrane Database Syst Rev. 2014;2014(10):CD009990. doi:10.1002/14651858.CD009990.pub2

11. Fanshawe TR, Halliwell W, Lindson N, Aveyard P, Livingstone-Banks J, Hartmann-Boyce J. Tobacco cessation interventions for young people. Cochrane Database Syst Rev. 2017;11(11):CD003289. doi:10.1002/14651858.CD003289.pub6

12. Villanti AC, West JC, Klemperer EM, et al. SmokingCessation Interventions for U.S. Young Adults: Updated Systematic Review. Am J Prev Med. 2020;59(1):123-136. doi:10.1016/j.amepre.2020.01.021

13. Suls JM, Luger TM, Curry SJ, Mermelstein RJ, Sporer AK, An LC. Efficacy of smoking-cessation interventions for young adults: a meta-analysis. Am J Prev Med. 2012;42(6):655-662. doi:10.1016/j.amepre.2012.02.013

14. Peirson L, Ali MU, Kenny M, Raina P, Sherifali D. Interventions for prevention and treatment of tobacco smoking in school-aged children and adolescents: A systematic review and meta-analysis. Prev Med. 2016;85:20-31. doi:10.1016/j.ypmed.2015.12.004

15. Stewart-Brown S. What is the evidence on school health promotion in improving health or preventing disease and, specifically, what is the effectiveness of the health promoting schools approach? World Health Organization, Regional Office for Europe; 2006. March 1, 2006. Accessed March 2, 2021. http://www.euro.who.int/ document/e88185.pdf

16. Dooris M. Healthy settings: challenges to generating evidence of effectiveness. Health Promot Int. 2006;21(1):55-65. doi:10.1093/heapro/dai030

17. Schreuders M, Nuyts PAW, van den Putte B, Kunst AE. Understanding the impact of school tobacco policies on adolescent smoking behaviour: A realist review. Soc Sci Med. 2017;183:19-27. doi:10.1016/j.socscimed.2017.04.031

18. Mélard N, Grard A, Robert PO, et al. School tobacco policies and adolescent smoking in six European cities in 2013 and 2016: A school-level longitudinal study. Prev Med. 2020;138:106142. doi:10.1016/j.ypmed.2020.106142

19. Kuipers MA, de Korte R, Soto VE, et al. School smoking policies and educational inequalities in smoking behaviour of adolescents aged 14-17 years in Europe. J Epidemiol Community Health. 2016;70(2):132-139. doi:10.1136/jech-2015-205831

20. Lorant V, Rojas VS, Robert PO, et al. Social network and inequalities in smoking amongst school-aged adolescents in six European countries. Int J Public Health. 2017;62(1):53-62. doi:10.1007/s00038-016-0830-z

21. Chyderiotis S, Benmarhnia T, Spilka S, et al. Why do apprentices smoke much more than high school students? Understanding educational disparities in smoking with a Oaxaca-blinder decomposition analysis. BMC Public Health. 2020;20(1):924. doi:10.1186/s12889-020-09050-4

22. Villanti AC, Niaura RS, Abrams DB, Mermelstein R. Preventing Smoking Progression in Young Adults: the Concept of Prevescalation. Prev Sci. 2019;20(3):377-384. doi:10.1007/s11121-018-0880-y

23. Moore GF, Audrey S, Barker M, et al. Process evaluation of complex interventions: Medical Research Council guidance. BMJ. 2015;350:h1258. doi:10.1136/bmj.h1258

24. Curran GM, Bauer M, Mittman B, Pyne JM, Stetler C. Effectiveness-implementation hybrid designs: combining elements of clinical effectiveness and implementation research to enhance public health impact. Med Care. 2012;50(3):217-226. doi:10.1097/MLR.0b013e3182408812

25. Denmark: preparatory education system reform. EU Cedefop. Denmark: preparatory education system reform. May 7, 2020. Accessed November 20, 2020. https://www. cedefop.europa.eu/en/news-and-press/news/denmarkpreparatory-education-system-reform

26. Bartholomew Eldredge LK, Markham CM, Ruiter RAC, et al. Planning health promotion program: an intervention mapping approach. Jossey-Bass; 2011.

27. Michie S, Hyder N, Walia A, West R. Development of a taxonomy of behaviour change techniques used in individual behavioural support for smoking cessation. Addict Behav. 2011;36(4):315-319. doi:10.1016/j.addbeh.2010.11.016

28. Ryan RM, Deci EL. Self-determination theory and the facilitation of intrinsic motivation, social development, and well-being. Am Psychol. 2000;55(1):68-78. doi:10.1037//0003-066x.55.1.68

29. Søgaard AJ, Selmer R, Bjertness E, Thelle D. The Oslo Health Study: The impact of self-selection in a large, population-based survey. Int J Equity Health. 2004;3(1):3. doi:10.1186/1475-9276-3-3

30. Scaccia JP, Cook BS, Lamont A, et al. A practical implementation science heuristic for organizational readiness: $\mathrm{R}=\mathrm{MC} 2$. J Community Psychol. 2015;43(4):484-501. doi:10.1002/jcop.21698

31. Pisinger V, Mikkelsen SS, Bendtsen P, Egan KK, Tolstrup JS. The Danish National Youth Study 2014: Study design, population characteristics and non-response analysis. Scand J Public Health. 2020;48(2):224-232. doi:10.1177/1403494817729283

32. Sundhedsstyrelsen. Danskernes Sundhed: Den Nationale Sundhedsprofil 2017. Sundhedsstyrelsen; 2018. Accessed March 2, 2021. https://www.sst.dk/-/media/ Udgivelser/2018/Den-Nationale-Sundhedsprofil-2017. ashx

33. Andersen A, Bast LS, Ringgaard LW, et al. Design of a school-based randomized trial to reduce smoking among 13 to 15-year olds, the X:IT study. BMC Public Health. 
2014;14:518. doi:10.1186/1471-2458-14-518

34. Borland R, Yong HH, O'Connor RJ, Hyland A, Thompson ME. The reliability and predictive validity of the Heaviness of Smoking Index and its two components: findings from the International Tobacco Control Four Country study. Nicotine Tob Res. 2010;12(Suppl 1):S45-S50. doi:10.1093/ntr/ntq038

35. Eisenberg ME, Forster JL. Adolescent smoking behavior: measures of social norms. Am J Prev Med. 2003;25(2):122128. doi:10.1016/s0749-3797(03)00116-8

36. Brown-Johnson CG, Cataldo JK, Orozco N, Lisha NE, Hickman NJ 3rd, Prochaska JJ. Validity and reliability of the Internalized Stigma of Smoking Inventory: An exploration of shame, isolation, and discrimination in smokers with mental health diagnoses. Am J Addict. 2015;24(5):410-418. doi:10.1111/ajad.12215

37. Carroll C, Patterson M, Wood S, Booth A, Rick J, Balain S. A conceptual framework for implementation fidelity. Implement Sci. 2007;2:40. doi:10.1186/1748-5908-2-40

38. Ferm L, Rasmussen CDN, Jørgensen MB. Operationalizing a model to quantify implementation of a multi-component intervention in a stepped-wedge trial. Implement Sci. 2018;13(1):26. doi:10.1186/s13012-018-0720-2

39. Ellard D, Parsons S. Process evaluation: understanding how and why interventions work. In: Thorogood M, Coombes Y, eds. Evaluating health promotion: practice and methods. Oxford University Press; 2010. doi:10.1093/acprof:oso/9780199569298.001.0001

40. Halkier B. Focus groups as social enactments: integrating interaction and content in the analysis of focus group data. Qual Res. 2010;10(1):71-89. doi:10.1177/1468794109348683

41. Kvale S, Birkmann S. Interview: Introduktion til et Håndværk. Hans Rietzels; 2009.

42. Alvesson M, Sköldberg K. Reflexive methodology: new vistas for qualitative research. 3rd ed. Sage; 2018.

43. Goffman E. Asylums: essays on the social situation of mental patients and other inmates. Anchor; 1961.

44. Berger PL, Luckmann T. The social construction of reality: A treatise in the sociology of knowledge. Penguin Group; 1966. Accessed March 2, 2021. http://perflensburg.se/ Berger\%20social-construction-of-reality.pdf

45. Miles MB, Huberman AM, Saldana J. Qualitative Data Analysis: A Methods Sourcebook. Sage; 2014.

46. Schreuders M, van den Putte B, Kunst AE. Smoke-free school policies in Europe: Challenges for the future. Prev Med. 2020;138:106130. doi:10.1016/j.ypmed.2020.106130

\section{ACKNOWLEDGEMENTS}

The Focus research group thanks all participating schools, students, teachers, principals as well as school coordinators. We thank student assistants who helped in data collection. We especially like to thank Camilla Øst Cloos for her contribution in the pilot study as well as assistance with data collection.

\section{CONFLICTS OF INTEREST}

The authors have each completed and submitted an ICMJE form for disclosure of potential conflicts of interest. The authors declare that they have no competing interests, financial or otherwise, related to the current work. All authors report funding from the Danish Cancer Society. C. Pisinger also reports that she is partly funded by the Danish Heart Association and a Danish non-profit fund, the Health Foundation. Funders had no influence on study choice, design, or interpretation.

\section{FUNDING}

This work was supported by the Danish Cancer Society (Proposal number R163-A10653).

\section{ETHICAL APPROVAL AND INFORMED CONSENT}

This study complies with the current Danish rules of ethics and legislature of the Danish Data Protection Agency (Ref: 17/12006). Ethical approval and informed consent were not required, as per National Committee on Health Research Ethics (Ref: 20182000-83).

\section{AUTHORS' CONTRIBUTIONS}

SA conceived the study and is the principal investigator and responsible for leading and directing the study. Furthermore, SA coordinates the study, participates in the collection of data, advises on statistical analyses, and interpretation of data. DD coordinates the study, participates in the collection of data, and conducts qualitative analyses. GSJ developed the student questionnaire, coordinates the study, participates in the collection of data, data cleaning, statistical analyses, interpretation of data and drafted the manuscript. JLV designed the teacher and principal questionnaires, coordinates the study and participates in the collection of data. MPJ designed the teacher and principal questionnaires, participates in the collection of data, data cleaning, statistical analyses, and interpretation of data. TH conceived the study, participated in the design of the study and supervises the research group. RK and CP participates in the design of the study and supervises the research group. All authors read, revised and approved the final version of the manuscript.

PROVENANCE AND PEER REVIEW

Not commissioned; externally peer reviewed. 